\title{
Measurements of Fingers Doses to Nuclear Medicine Staff
}

\author{
S. H. A. ALLehyani ${ }^{1}$, R. A. Hassan ${ }^{1,2}$ \\ ${ }^{1}$ Department of Physics, Faculty of Applied Sciences, Umm Al Qura University, Makkah, Saudi Arabia \\ ${ }^{2}$ Department of Nuclear physics, National Cancer Institute, Cairo University, Cairo, Egypt
}

\begin{abstract}
Background: For some occupationally radiation exposed groups, the hands are more heavily exposed to ionizing radiation than the rest of the body. Method: In this study, finger doses were measured for five different nuclear medicine staff occupational groups for which heavy irradiation of the hands was suspected. Finger doses were measured for Nuclear medicine physicians, technologists, nurses and physicists. The nuclear medicine staff working with the radioactive materials wear two TLD dosimeter during the whole period, which lasted from 1 to 4 weeks. staff perform their work on a regular basis throughout the month, and mean annual doses were calculated for these groups. Results: The maximum average dose was to the technologists handled therapeutic ${ }^{131}$ I finger in this study (2.8 $\mathrm{mSv}$ ). Doses to the fingers also were found to be slightly higher in a nurses Physicians do not work on a regular basis, and finger doses received by this group were too small and too irregular to consider. Conclusion: We conclude that the maximum expected annual dose to the extremities appeared to be less than the annual limit ( $500 \mathrm{mSv} / \mathrm{y})$ because all of these workersare on rotation and do not constantly handle radioactivity throughout the year.
\end{abstract}

Keywords: Finger radiation dose; TLD; Nuclear medicine staffs

\section{Introduction}

A very important part of following As Low As Reasonably Achievable (ALARA) principles and determining whether personnel are being excessively exposed to radioactivity either due to poor handling techniques on the part of the worker or the use of a system that permits contamination - is the establishment of a formal program for personnel monitoring and bioassay [1]. Nuclear medicine laboratories use the majority of their radioactive elements for diagnostic and therapeutic purposes, such as technetium ${ }^{99 \mathrm{~m}} \mathrm{Tc}$, Iodine ${ }^{131} \mathrm{I}$, gallium ${ }^{67} \mathrm{Ga}$, Thallium ${ }^{201} \mathrm{Tl}$ and other radioactive elements that emit gamma and beta radiation[2]. Nuclear medicine workers handling these isotopes are exposed to ionizing radiation. In laboratories, a whole-body dose is typically monitored by means of an individual thermoluminescent dosimeter (TLD). Lead or lead glass shields used in laboratories minimize whole-body doses received by workers. Nevertheless, aspects of laboratory job have to be performed manually, and hence hands are most commonly exposed to radiation. Over the course of a year, several thousand examinations are carried out, and the activity involved is of the order of GBq. We present results of measurements of equivalent doses to the hands of workers employed in selected nuclear medicine laboratories, in which technetium and iodine are commonly used. Such monitoring is necessary to ensure that personnel exposure to radiation is maintained within relevant dose limits. We also investigate the monitoring of new techniques to ensure that the adoption of these new techniques does not cause an unacceptable level of radiation exposure. Several workers, including physicians, nurses, technicians and physicists, were included in the study. Doses were measured at 1-month intervals. A dose equivalent limit to the hands was $500 \mathrm{mSv}$ [3]. TLD chips are normally used to measure radiation doses to the fingers of staff involved in handling radioactive materials $[\underline{4}, \underline{5}]$. The purpose of the study is to measure the actual fingers doses received by physicians, nurses, technicians and physicists who worked in Nuclear Medicine.

\section{Description of Actual Work}

TLDs (Harshaw Inc.,) consisting of squares measuring 0.35 $\mathrm{mm}$ (diameter) $\times 0.35 \mathrm{~mm}$ (thickness) were used in this study for measuring finger doses of staff handling ${ }^{99 \mathrm{~m}} \mathrm{Tc}$ labeled compounds and ${ }^{131} \mathrm{I}$ for diagnosis cases. Before each irradiation, detectors were placed in a standard annealing oven for $10 \mathrm{~min}$ (for TLD-MCP-Ns (TL dosimeters designed to measure personal dose equivalent $\mathrm{Hp}(0.07)$ in fields of weakly penetrating radiation)) at $240^{\circ} \mathrm{C}$ followed by rapid cooling to room temperature. MCP-Ns detectors were submitted to a $50 \mathrm{~s}$ preheat at $240^{\circ} \mathrm{C}$ with a linear rating of $10^{\circ} \mathrm{Cs}^{-1}$ and maximum annealing temperature of $240^{\circ}$ C.The dosimeters were calibrated using an Sr-90 irradiator, thermo-thermo-electron manufacture The sensitivity variations of the TLDs that we used were less than $\pm 10 \%$. The TLDs were inserted in a plastic ring holder that could be adjusted for any finger size. The occupational workers wore the TLDs at the base of a finger on their operating hand. The workers wearing TLDs were advised to wear rubber gloves over the dosimeters to avoid any possible radioactive contamination. The TLDs were kept in a low-background-radiation area when not in use. Five groups of workers were evaluated. Group 1 consisted of four physicians. The nuclear medicine physicians were involved in checking patients or, after the imaging, in monitoring patients with differentiated thyroid cancer and thyrotoxicosis. Group 2 consisted of five technologists. These workers were involved in the elution and preparation of ${ }^{99 \mathrm{~m}} \mathrm{Tc}$-labeled compounds for diagnostic procedures. These individuals also loaded individual doses of ${ }^{99 \mathrm{~m}} \mathrm{Tc}$ labeled radiopharmaceuticals into syringes and positioned and imaged the patients. Group 3 consisted of five nurses who gave intravenous administrations to patients for $g$ camera imaging. Group 4 consisted of two physicists who were involved in the quality control of the imaging and 


\section{International Journal of Science and Research (IJSR) \\ ISSN (Online): 2319-7064}

Index Copernicus Value (2013): 6.14 | Impact Factor (2015): 6.391

non-imaging systems in the nuclear medicine department in the context of non-uniformity and sensitivity checks for the gamma camera. Group 5 consisted of three technologists. These workers were involved in handling therapeutic quantities of ${ }^{131} \mathrm{I}$ for treating patients with differentiated thyroid cancer and thyrotoxicosis and routine monitoring of patients in an isolation ward. The workers used a syringe shield while handling radioactive elements. The use of a syringe shield is recommended from a radiation safety standpoint. A control ring was kept in a low-backgroundradiation area for measuring the background response of the TLD. The staff used the ring dosimeters for 1 week and returned them for measurements. Some of the staff were issued another batch of ring dosimeters for the next week if they had to perform identical work. The process was repeated for 4 weeks for some of the workers. Thus, we could measure the finger doses for workers for periods ranging from 1-4 weeks. Doses to the finger base were measured for the ring fingers of both hands for only 1 week. Exposed TLDs were read with a Harshaw TLD reader. The doses were expressed in microsieverts $(\mu \mathrm{Sv})$ or millisieverts $(\mathrm{mSv})$ using dose-response (calibration) curves for ${ }^{99 \mathrm{~m}} \mathrm{Tc}$ and ${ }^{131} \mathrm{I}$ gamma rays[6].

\section{Results}

TLD disks irradiated with different doses of gamma photons from ${ }^{99 \mathrm{~m}} \mathrm{Tc}$ and ${ }^{131} \mathrm{I}$ were placed in the TLD reader and the average response (counts) of three TLDs inside each holder was obtained and corrected for the background. The method used for the calibration procedure is described elsewhere []. The radiation-weighting factor for the gamma photons from both ${ }^{131} \mathrm{I}$ and ${ }^{99 \mathrm{~m}} \mathrm{Tc}$ was taken to be 1 . Table 1 lists the radiation doses to the fingers for workers in Group 1. As expected, the radiation doses to the fingers of the physicians involved in just checking patients and not handling radioactive materials directly were observed to be lower. The technologists (table 2)in Group 2 worked in the ${ }^{99 \mathrm{~m}} \mathrm{Tc}$ radiopharmacy laboratory in addition to their routine duties with gamma camera imaging; this schedule led to finger doses that were higher than those of the physician group. Table 3 lists the finger doses for Group 3 workers (nurses). The nurses administered doses of ${ }^{99 \mathrm{~m}} \mathrm{Tc}$-labeled compounds to patients. The doses to the fingers of the nurses were lower than those to the Group 2 technologists. Table 4 show the doses received by two Physicians in group 4 for both bands as cross chick to table one for one week which found negligible because they are not involved in preparing and administering therapeutic doses of radioiodine to patients as mentioned before. The doses of ${ }^{131}$ I for the technologists group are listed in Table 5; these workers were involved in preparing and administering therapeutic doses of radioiodine to patients with thyroid cancer and thyrotoxicosis. Two technologists were involved in the routine monitoring of patients, and the third technologist was involved in imaging the patients before and after radioiodine therapy. The maximum dose was observed for the finger of (Tech3) in Group 5 who handled a large quantity of radioiodine for therapy. The dose range and the mean dose to the fingers of workers in Groups 2, 3 and 4 are listed in Table 6.With this level of exposure (average) to handling ${ }^{99 \mathrm{~m}}$ Tc-labeled compounds, the exposure would not be expected to exceed the prescribed annual limit of $500 \mathrm{mSv}$ for any worker, particularly when duties change periodically from one area to another. All of the areas of work examined in this study had the highest potential for exposure to the fingers. The dose range and the mean doses of fingers of workers in Group 5 also are listed in Table 6. With this level of exposure (average) in handling ${ }^{131} \mathrm{I}$, exposures could exceed the annual limit of $500 \mathrm{mSv}$ if workers continued to perform the same work throughout the year. However, in our facility, each technologist is involved in therapeutic ${ }^{131} \mathrm{I}$ procedures for a period not exceeding 6 months, under the supervision of a consultant. The finger doses per unit of activity for the physicians group are not listed in Table 6 because physicians did not handle radioactive materials directly.

Table 1: Finger Doses for Group 1 Workers (Physicians)

\begin{tabular}{|c|c|c|c|c|}
\hline $\begin{array}{c}\text { Workers } \\
\text { (Physicians) }\end{array}$ & $\begin{array}{c}\text { Activity } \\
\text { Handled/1 } \\
\text { Week (GBq) }\end{array}$ & \multicolumn{2}{|c|}{$\begin{array}{c}\text { Hand } \\
\text { Doses (mSv) } \\
\text { Accumulated in } \\
1 \text { Week }\end{array}$} & $\begin{array}{c}\text { Mean } \pm \text { SD }{ }^{\#} \text { Finger } \\
\text { Dose }(\mathrm{mSv}) \\
\text { Accumulated in 1 } \\
\text { Week for Both } \\
\text { Hands }\end{array}$ \\
\hline Phyn1 & & Right & Left & \\
\hline Phyn2 & & 0.1 & 0.1 & $0.1 \pm 0$ \\
\hline Phyn3 & & 0.3 & 0.2 & $0.25 \pm 0.07$ \\
\hline Phyn4 & & 0.1 & 0.2 & $0.15 \pm 0.07$ \\
\hline
\end{tabular}

*standard Deviation

Table 2: Finger Doses for Group 2 Workers (Technologists)

\begin{tabular}{|c|c|c|c|c|}
\hline $\begin{array}{c}\text { Workers } \\
\text { (Technologist) }\end{array}$ & $\begin{array}{c}\text { Activity } \\
\text { Handled/ } \\
\text { 1 Week } \\
(\mathrm{GBq})\end{array}$ & $\begin{array}{c}\text { Hand } \\
\text { Doses }(\mathrm{mSv}) \\
\text { Accumulated in 1 } \\
\text { Week }\end{array}$ & $\begin{array}{c}\text { Mean } \pm \text { SD Finger } \\
\text { Dose }(\mathrm{mSv}) \\
\text { Accumulated in 1 } \\
\text { Week for Both } \\
\text { Hands }\end{array}$ \\
\cline { 3 - 4 } & Right & Left & $2.3 \pm 0.28$ \\
\hline Tech1 & 96.2 & 2.5 & 2.1 & $2.3 \pm 0.07$ \\
\hline Tech2 & 81.4 & 2.2 & 2.3 & $2.25 \pm 0.07$ \\
\hline Tech3 & 22.2 & 0.8 & 0.9 & $0.85 \pm 0.07$ \\
\hline Tech4 & 79.5 & 1.9 & 2 & $1.95 \pm 0.07$ \\
\hline Tech5 & 35.1 & 0.7 & 0.8 & $0.75 \pm 0.07$ \\
\hline
\end{tabular}

Table 3: Finger Doses for Group 3 Workers (Nurses)

\begin{tabular}{|c|c|c|c|c|}
\hline $\begin{array}{c}\text { Workers } \\
\text { (Nurses) }\end{array}$ & $\begin{array}{c}\text { Activity } \\
\text { Handled/ } \\
\text { 1 Week (GBq) }\end{array}$ & \multicolumn{2}{|c|}{$\begin{array}{c}\text { Hand } \\
\text { Doses (mSv) } \\
\text { Accumulated in } \\
\text { 1 Week }\end{array}$} & $\begin{array}{c}\text { Mean } \pm \text { SD Finger } \\
\text { Dose (mSv) } \\
\text { Accumulated in 1 } \\
\text { Week for Both } \\
\text { Hands }\end{array}$ \\
\cline { 3 - 4 } & Right & Left & $1.8 \pm 0.14$ \\
\hline N1 & 81.4 & 1.9 & 1.7 & $1.95 \pm 0.07$ \\
\hline N2 & 79.5 & 1.9 & 2 & 1.95 \\
\hline N3 & 35.1 & 1.3 & 1.2 & $1.25 \pm 0.07$ \\
\hline N4 & 35.1 & 1.5 & 1.1 & $1.3 \pm 0.28$ \\
\hline N5 & 22.2 & 0.4 & 0.5 & $0.45 \pm 0.07$ \\
\hline
\end{tabular}

Table 4: Finger Doses for Group 4 Workers (Physicists)

\begin{tabular}{|c|c|c|c|c|}
\hline \multirow[t]{2}{*}{$\begin{array}{l}\text { Workers } \\
\text { (Physicists) }\end{array}$} & \multirow{2}{*}{$\begin{array}{l}\text { Activity } \\
\text { Handled/ } \\
1 \text { Week } \\
(\mathrm{GBq})\end{array}$} & \multicolumn{2}{|c|}{$\begin{array}{c}\text { Hand Doses }(\mathrm{mSv}) \\
\text { Accumulated in } 1 \\
\text { Week }\end{array}$} & \multirow{2}{*}{$\begin{array}{c}\text { Mean } \pm \text { SD Finger } \\
\text { Dose }(\mathrm{mSv}) \\
\text { Accumulated in } 1 \\
\text { Week for Both Hands }\end{array}$} \\
\hline & & Right & Left & \\
\hline Phys1 & 9.4 & 0.2 & 0.2 & $0.2 \pm 0.0$ \\
\hline Phys2 & 9.2 & 0.2 & 0.1 & $0.15 \pm 0.07$ \\
\hline
\end{tabular}




\section{International Journal of Science and Research (IJSR) ISSN (Online): 2319-7064}

Index Copernicus Value (2013): 6.14 | Impact Factor (2015): 6.391

Table 5: Finger Doses for Group 5 Workers (Technologists Handling $\left.{ }^{131} \mathrm{I}\right)$.

\begin{tabular}{|c|c|c|c|c|}
\hline \multirow[t]{2}{*}{$\begin{array}{c}\text { Workers } \\
\text { (Technologists) }\end{array}$} & \multirow[t]{2}{*}{$\begin{array}{c}\text { Activity } \\
\text { Handled/ } \\
1 \text { Week } \\
\text { (GBq) }\end{array}$} & \multicolumn{2}{|c|}{$\begin{array}{c}\text { Hand Doses } \\
(\mathrm{mSv}) \\
\text { Accumulated in } 1 \\
\text { Week }\end{array}$} & \multirow{2}{*}{\begin{tabular}{|c|} 
Mean \pm SD \\
Finger Dose \\
$(\mathrm{mSv})$ \\
Accumulated in \\
1 Week for Both \\
Hands
\end{tabular}} \\
\hline & & Right & Left & \\
\hline Tech1 & 11.1 & 1.7 & 1.5 & $1.6 \pm 0.14$ \\
\hline Tech2 & 18.5 & 2.5 & 2 & $2.25 \pm 0.35$ \\
\hline Tech3 & 22.2 & 2.8 & 2.2 & $2.5 \pm 0.42$ \\
\hline
\end{tabular}

Table 6: Dose Range and Mean Doses to Fingers of

Workers Involved in Handling Radiopharmaceuticals

\begin{tabular}{|c|c|c|c|c|}
\hline \multirow{2}{*}{ Group } & \multirow{2}{*}{ Workers } & \multicolumn{2}{|c|}{ Dose Range $(\mu \mathrm{Sv} / \mathrm{GBq})$} & $\begin{array}{c}\text { Mean } \pm \mathrm{SD} \\
\text { Mean } \pm \mathrm{SD}\end{array}$ \\
\cline { 3 - 4 } & & Minimum & Maximum & $\begin{array}{c}\text { Finger Dose } \\
(\mu \mathrm{Sv} / \mathrm{GBq})\end{array}$ \\
\hline 1 & $\begin{array}{c}99 \mathrm{~m} \mathrm{Tc}- \\
\text { Technologists }\end{array}$ & 19.94 & 40.54 & $30.24 \pm 14.5$ \\
\hline 2 & Nurses & 18.02 & 42.74 & $30.37 \pm 17.5$ \\
\hline 3 & Physicists & 10.87 & 21.74 & $16.3 \pm 7.7$ \\
\hline 4 & $\begin{array}{c}{ }^{131} \mathrm{I} \text { - } \\
\text { Technologists }\end{array}$ & 99.1 & 153.2 & $126.13 \pm 38.2$ \\
\hline
\end{tabular}

Finger doses can serve as a guide to suggest any needed modification in work practices to minimize radiation doses to the extremities. For all of the workers in this study, doses to the ring fingers that accumulated in 1 week suggested that exposure was not likely to exceed the annual limit of $500 \mathrm{mSv}$ in our facility. The maximum average dose to a worker's finger in this study was $2.8 \mathrm{mSv}$, accumulated over 1 week, suggesting that the annual dose for the worker would not reach the annual limit of $500 \mathrm{mSv}$ if the worker continued to perform the same type of work throughout the year. The technologists in this study handled therapeutic ${ }^{131}$ I for a period of 2 months over a span of 3 years. In this study, we selected the workers and the type of work with the highest potential for exposure of the extremities, particularly the fingers. However, the chance of exceeding the prescribed annual limit for these workers was remote in our practice.

The annual equivalent doses to finger have been reported to potentially not exceed the annual limit of $500 \mathrm{mSv}$ [7-9]. To follow ALARA, we must control exposure to the fingers; syringe shields made of lead or tungsten are normally used. A dose rate of $1.35-1.62 \mathrm{mGy} / \mathrm{h} / \mathrm{MBq}$ was reported when activity was contained in disposable syringes shielded by lead glass ${ }^{(9)}$. The syringe shield is one of the devices used to minimize radiation doses to fingers during injections; the use of specialized syringe calibrators reduces the doses to fingers during dose measurements with calibrators $[10,11]$.The use of syringe shields can reduce finger doses by $75-85 \%$, and doses received from individual injections vary from $1-150 \mathrm{mGy}$, depending on the degree of difficulty experienced during injection [12]. Finger doses can be reduced by the use of a short-tubing butterfly cannula inserted into the veins of patients before radiopharmaceutical administration [13] . The ${ }^{99 \mathrm{~m}} \mathrm{Tc}$ technologist workers who handled the maximum activity of ${ }^{99 \mathrm{~m}} \mathrm{Tc}$ during the period of this study showed a finger dose of $2.3 \pm 0.28 \mathrm{mSv}$ accumulated over the course of 1 week. If these workers continued to perform the same procedures throughout the year, their finger doses probably would not exceed $115 \mathrm{mSv}$ (maximum: $125 \mathrm{mSv}$ ) in 1 year.

In this study, relatively lower finger doses were observed for physicists handling ${ }^{99 \mathrm{~m}} \mathrm{Tc}$ for quality-control procedures. Doses to the fingers also were found to be slightly higher in a nurses involved in the administration of doses of ${ }^{99 \mathrm{~m}} \mathrm{Tc}$-labeled compounds to patients. The 1-week accumulated dose to fingers was found to be $1.95 \pm 0.07$ $\mathrm{mSv}$; this dose could lead to an annual dose of $97.5 \mathrm{mSv}$. The highest finger doses reported at the radio pharmacy and dispensary in 1 week were $6.8 \mathrm{mSv}$, which corresponds to an annual dose of $330 \mathrm{mSv}$ [14]. At the same center, weekly and annual doses during the administration of injections were recorded to be 4.6 and $220 \mathrm{mSv}$, respectively. In the present study, the highest finger dose that accumulated in 1 week for a ${ }^{131} \mathrm{I}$ technologist was observed to be $2.5 \pm 0.42 \mathrm{mSv}$. At our center, each technologist performed work for a period not exceeding 2 months. This situation is applicable to all of the technologists since they are on rotation, except for the consultant in charge of ${ }^{131} \mathrm{I}$ treatments, who supervises all of the treatments throughout the year. In our practice, exposure is not likely to exceed the annual limit of 500 $\mathrm{mSv}$ for any technologist under normal prevailing work circumstances. A convenient method is to use a ring TLD for measuring doses of the diagnostic units of different nuclear medicine facilities. The doses of the TLDs were reported in $\mathrm{mSv}$ that had accumulated over 1 week. We measured the radiation doses to the hands of nuclear medicine staff at the hospitals being studied. The maximum expected annual dose to the extremities appeared to be less than the annual limit $(500 \mathrm{mSv} / \mathrm{y})$ because all of these workers were on rotation and did not constantly handle radioactivity throughout the year. Radiation doses per unit of activity ( $\mathrm{mSv} / \mathrm{GBq})$ to the base ring fingers of nursing staff were observed to be nearly the same as those for ${ }^{99 \mathrm{~m}} \mathrm{Tc}$ technologists involved in giving injections of ${ }^{99 \mathrm{~m}} \mathrm{Tc}$-labeled compounds. The mean finger dose per unit of activity $(\mathrm{mSv} / \mathrm{GBq})$ for technologists handling ${ }^{131} \mathrm{I}$ was found to be 4.17 times higher than that for technologists involved in injecting ${ }^{99 \mathrm{~m}} \mathrm{Tc}$-labeled compounds. The doses of the righthand fingers for most workers in this study were slightly higher than those of the left fingers; the main reason for this elevated dose is thought to be due to handling radioactive isotope using their right haands. Annual doses to the extremities were not likely to exceed the annual dose limit, further indicating the safety of the operational practice. Tocontrol exposure to the fingers, syringe shields made of leador tungsten are recommended. It is advised to clean the fume hood and remove the contaminated sheet daily to minimize doses to the extremities. The staff handling radioactive materials could benefit from practicing with dummy sources that would allow them to become familiar with the procedures and optimize their handling techniques. Such practices also could improve radiation safety awareness and minimize the potential for contamination. With adequate radiation safety standards and good work practice, there is a good chance that exposure will not exceed the annual limit of $500 \mathrm{mSv}$ for the extremities. This survey represent only finger doses to 


\section{International Journal of Science and Research (IJSR) \\ ISSN (Online): 2319-7064}

Index Copernicus Value (2013): 6.14 | Impact Factor (2015): 6.391

Nuclear Medicine staff at National cancer institute, in Cairo, Egypt.

\section{Acknowledgments}

The authors wish to thank the staff of the Nuclear Medicine department of AL-noor Specialist Hospital in Makkah , Saudi Rabia for their support!

\section{References}

[1] D. Keskintepe AYO: A Study on Personnel Dosimeters. Fabad J Pharm Sci. (2004); 29:77-80.

[2] Rollo.F.D. Nuclear medicine physics, instrumentation, and agents first edition . (1977).

[3] Council Directive 96/29/EURATOM of laying down Basic Safety Standards for the Protection of the Health of Workers and the General Public against the Dangers arising from Ionizing Radiation. Official Journal of the European Communities. (1996); 39:1-114.

[4] WILLIAMS ED, LAIRD EE, FORSTER E. Monitoring radiation dose to the hands in nuclear medicine: location of dosemeters. Nuclear Medicine Communications. (1987); 8:499-503.

[5] MACKENZIE A. Reduction of extremity dose in the radiopharmacy. Nuclear Medicine Communications (1997), 18:578-581.

[6] Pant GS, Sharma SK, Bal CS, Kumar R, Rath GK: Radiation dose to family members of hyperthyroidism and thyroid cancer patients treated with 131I. Radiation Protection Dosimetry. (2006); 118:22-27.

[7] Chru_cielewski W, Olszewski J, Jankowski J, Cygan M. Hand Exposure in Nuclear Medicine Workers. Radiation Protection Dosimetry (2002); 101:229-232.

[8] Pant GS, Sharma SK, Rath GK: Finger Doses for Staff Handling Radiopharmaceuticals in Nuclear Medicine. Journal of Nuclear Medicine Technology. (2006), 34:169-173.

[9] Prussin SG, Theofanous G, Casey D, Kim A: Dose from Syringe Procedures During Technetium-99m Radiopharmaceutical Preparation. Journal of Nuclear Medicine Technology. (1998); 26:32-37.

[10]Chiesa C, De Sanctis V, Crippa F, Schiavini M, Fraigola EC, Bogni A, Pascali C, Decise D, Marchesini $\mathrm{R}$, Bombardieri E. Radiation dose to technicians per nuclear medicine procedure: comparison between technetium-99m, gallium-67, and iodine-131 radiotracers and fluorine-18 fluorodeoxyglucose.European Journal of Nuclear Medicine. (1997); 24:1380-1389.

[11] HASTINGS DL, HILLEL PG, JEANS SP, WALLER ML. An assessment of finger doses received by staff while preparing and injecting radiopharmaceuticals. Nuclear Medicine Communications .1997; 18:785-790.

[12] Whitby M, Martin CJ: Investigation using an advanced extremity gamma instrumentation system of options for shielding the hand during the preparation and injection of radiopharmaceuticals. Journal of Radiological Protection. (2003); 23:79.

[13]BATCHELOR S, PENFOLD A, ARIC I, HUGGINS R. Radiation dose to the hands in nuclear medicine. Nuclear Medicine Communications. (1991); 12:439444.
[14]HARDING LK, HESSLEWOOD S, GHOSE SK, THOMSON WH: The value of syringe shields in a nuclear medicine department. Nuclear Medicine Communications. (1985); 6:449-454.

Volume 5 Issue 6, June 2016 www.ijsr.net 